\title{
Hemodiyaliz hastalarında uyku kalite bozukluğu ve huzursuz bacak sendromu arasındaki ilişki
}

\author{
Relationship between restless leg syndrome an quality of sleep disorders in \\ hemodialysis patients
}

Can Hüzmeli*, Ferhan Candan, Ayşe Şeker Koçkara, Lale Akkaya, Mansur Kayataş

Nefroloji Anabilim Dalı (Dr. C. Hüzmeli, Prof. Dr. F. Candan, Dr. A. Ş. Koçkara, Prof. Dr. M. Kayataş, Hemş. L. Akkaya), Cumhuriyet Üniversitesi Tıp Fakültesi, TR-58140 Sivas

\begin{abstract}
Özet
Amaç. Huzursuz bacak sendromu (HBS) bacaklarda huzursuzluk hissi, yanma ile kendini gösteren istirahat ve geceleri daha sık olan bacakları hareket ettirme isteği ile karakterize bir rahatsızlıktır. $\mathrm{Bu}$ durum hemodiyaliz hastalarında sıktır ve uykusuzluğa neden olabilir. Biz çalışmamızda uyku kalitesinde bozukluk ile HBS arasındaki ilișkiyi incelemeyi amaçladık. Yöntem. Calıșmaya hemodiyaliz programında olan hastalar alındı. Hastalara Uluslar arası huzursuz bacak çalışma grubu tanı kriterleri kullanıldı ve uyku kalitesi bozukluğu için Pittsburg uyku kalitesi indeksi kullanıldı. Hastaların tümünde hemogram, PTH, kalsiyum, fosfor, kreatinin, demir, serum demir bağlama kapasitesi ve ferritin değerleri değerlendirildi. Bulgular. Çalışmaya 112 hemodiyaliz hastası alındı. Hastaların yaş ortalaması 56,8 $\pm 16,2$ idi. Hastaların \%61,6'sında uyku kalitesinde bozukluk ve \%66,1'inde HBS tespit edildi. Uyku kalite bozukluğu ile HBS arasında anlamlı bir ilişki $(p<0.05)$ saptandı. Uyku kalitesinde bozukluk ve HBS'nun anemi, PTH, kalsiyum ve fosfor değerleriyle anlamlı bir ilişkisi saptanmadı. Sonuç. Çalışmamızda uyku kalitesinde bozukluk ile HBS arasında anlamlı bir ilişki saptandı. Hemodiyaliz hastalarında uyku kaliteside bozukluk ve HBS sık olmasına rağmen etyolojisi net bilinmemektedir. HBS semptomlarının gece daha sık olmasından dolayı uyku kalitesinin bozukluklarına neden olabileceği düşünülmektedir.
\end{abstract}

Anahtar sözcükler: Huzursuz bacak sendromu, uyku kalitesinde bozukluk, hemodiyaliz

\begin{abstract}
Aim. Restless legs syndrome (RLS) an ilness characterized by discomfort in the legs, rest manifested by burning and a desire to move the legs more often at night. This situation is common in hemodialysis patients and can cause insomnia. In our study, we aimed to investigate the relationship between the RLS and quality of sleep disorders. Methods. The study enrolled patients who were receiving hemodialysis. The international restless legs study group criteria were used for patients and the Pittsburg sleep quality index was used for sleep disturbance. In all patients, complete blood count, PTH, calcium, phosphorus, creatinine, iron, serum iron binding capacity and ferritin levels were evaluated. Results. The study enrolled 112 hemodialysis patients. The mean age of patients was $56.8 \pm 16.2$. In patients $61.6 \%$ the disorder in sleep quality was detected and in $66.1 \%$ the RLS was detected. A significant relationship between quality of sleep disorders and RLS $(\mathrm{p}<0.05)$ were detected. A significant association among disorders in sleep quality and RLS anemia, PTH, calcium and phosphorus levels were not detected. Conclusion. In our study, a significant relationship between quality of sleep disorders and RLS was detected. In hemodialysis patients, disorders in sleep quality and RLS is more common, but its etiology is unclear. Due to RLS symptoms more often at the night it is thought to be lead to quality of sleep disorders.
\end{abstract}

Keywords: Restless legs syndrome, quality of sleep disorders, hemodialysis 
Geliş tarihi/Received: 20 Şubat 2014; Kabul tarihi/Accepted: 04 Aralık 2014

\author{
*İletişim adresi: \\ Dr. Can Hüzmeli, Nefroloji Anabilim Dalı, Cumhuriyet Üniversitesi Tıp Fakültesi, TR-58140 \\ Sivas. E-posta: chuzmeli@hotmail.com
}

\title{
Giriş
}

Huzursuz bacak sendromu (HBS) parestezi ve yanma hissi ile kendini gösteren, istirahat sırasında ve geceleri hastaların etkilenen ekstremitelerini (genellikle bacaklar) hareket ettirme isteği ile karakterize bir rahatsızlıktır. Semptomların istirahat halinde ortaya çıkması ve giderek artması ile geceleri ve uyku esnasında daha belirgin olması tipiktir. Hastalık aralıklı olarak alevlenir ve uzun süreli asemptomatik dönemler olabilir. Epidemiyolojik çalışmalara göre HBS, populasyonuın \%1-15 kadarında görülebilmektedir. Kadınlarda iki kat daha fazladır ve özellikle yaşlılarda ( $>65$ yaş) daha sık görülmektedir [1-4] HBS'da tanı için ayrıntılı bir anamnez gereklidir ve Uluslararası HBS çalışma grubu tanı kriterleri kullanılır. HBS'nun şiddetini derecelendirmek için HBS çalışma grubu tarafından derecelendirme ölçeği oluşturulmuştur. Bu ölçekteki puanlama sistemine göre, 1-10 arası puan hafif, 11-20 arası orta, 21-30 arası şiddetli, 31-40 arası ise çok şiddetli derecede HBS'nu göstermektedir [5]. HBS olan hastalarda uyku kalitesinde bozuklukları (\%10-20) ve uykuda uzuv hareketleri oldukça sık görülmektedir [3,6]. Uyku kalitesinde bozukluklar son dönem böbrek yetmezliği sebebiyle hemodiyalize alınan hastalar arasında sik rastlanmaktadır. Öyle ki bu hastaların dörtte üçünden fazlasında, bir veya daha fazla subjektif uyku yakınmasının olduğu gösterilmiştir. Genel populasyonda \%5-10 olan HBS, diyaliz hastalarında \%80'e ulaşabilmektedir [7]. Uluslararası HBS Çalışma grubunun HBS minimal kriterleri ile tanınabilen huzursuz bacak sendromu, idiyopatik olabileceği gibi gebelik, üremi ve romatoid artrit gibi durumlara sekonder olarak gelişebilir $[8,9]$.

Hemodiyaliz hastalarında uyku sorunlarına sık rastlanmaktadır. Prevalansnın \%50 ile \%83 arasında olduğu tahmin edilmektedir. Uyku sorunları, hemodiyaliz hastalarının özbakım gücü ve yaşam kalitesi üzerinde olumsuz etkiler yaratabilmektedir. HD hastalarında gece etkin uyuma sağlanamadığı için, gündüz kısa uyuklamalar sıkça gözlenmektedir. Hemodiyaliz hastalarında uyku kalitesinin bozukluklarını değerlendirmek için Pittsburg uyku indeksi kullanılabilir. Son bir aylık uyku kalitesini belirlemede yaygın olarak kullanılan Pittsburg uyku kalite indeksi (PUKİ) güvenilir ve tutarlı bir ankettir [10]. Son dönem böbrek yetmezliği nedeniyle hemodiyaliz tedavisi programında olan hastalarda uyku yakınmalarının tipi ve sıklığı ile ilgili çok sayıda çalışma olmasına karşın, PUKİ kullanılarak uyku kalitesinin değerlendirildiği çalışma sayıs1 azdır [11].

$\mathrm{Bu}$ çalışmada amaç, hemodiyaliz hastalarında sık olan ve etyolojisi tam bilinmeyen HBS'nun Sivas ilimizde sıklığını ve şiddetini belirlemek. Ayrıca hemodiyaliz hastalarında HBS'nun uyku kalite bozukluğuna etkisini araştırmayı amaçladık.

\section{Gereç ve yöntem}

Çalışmamız, Cumhuriyet Üniversitesi Etik Kurulu tarafından onaylandıktan sonra çalışmaya başlandı. Çalışmaya en az üç aydan beri haftada 3 gün 4 saat hemodiyaliz programındaki hastalar alındı, zihinsel özürlü, hemiplejik hastalar, kalp yetmezliği ve kronik obstrüktif akciğer hastalıkları çalışmaya alınmadı. Çalışmamız Sivas'ta hemodiyalize giren 112 hastada yapıldı. Çalışmaya alınan hastaların imzalı onamı alındı. Hastalarda hemodiyaliz girişi kanları çalışıldı.

Son bir aylık uyku kalitesini belirlemede yaygın olarak kullanılan Pittsburg uyku kalitesi indeksi güvenilir ve tutarlı bir anket olup, birçok hasta grubunda uygulanmaktadır [10, 
12]. PUKİ; subjektif uyku kalitesi, uyku gecikmesi, uyku süresi, uyku verimliliği, uyku bozukluğu, uyku ilacı kullanımı ve gündüz işlerinde bozulmanın değerlendirildiği yedi ögeden oluşmaktadır. Her birinin yanıtı belirti sıklığına göre 0-3 arasında puanlanmaktadır. Puanlama; geçen ay boyunca hiç olmamışsa 0 , haftada birden az ise 1 , haftada bir veya iki kez ise 2 , haftada 3 veya daha fazla ise 3 olarak yapılmaktadır. Ankette sorulan uyku kalitesi değerlendirilmesi ise; çok iyi 0 , oldukça iyi 1 , oldukça kötü 2, çok kötü 3 olarak puanlanmaktadır. Elde edilen global skor 0-21 arasında değişmekte ve yüksek değerler uyku kalitesinin kötü, uyku bozukluğu seviyesinin yüksek olduğunu göstermektedir. Global skorun 5 veya üzerinde olması klinik olarak uyku kalitesinin anlamlı düzeyde kötü olduğunu göstermektedir. Tanısal duyarlılığı \%89,6; özgüllüğü $\% 86,5$ 'tir $[13,14]$. Tablo 1'de uyku kalitesi anketi görülmektedir.

Tablo 1. Uyku kalite indeksi.

\begin{tabular}{|c|c|c|c|c|}
\hline $\begin{array}{l}\text { Subjektif uyku kalitesi(uyku } \\
\text { kalitesini kişinin kendisinin } \\
\text { değerlendirmesi }\end{array}$ & $\begin{array}{l}\text { Çok iyi } \\
\text { Puan=0 }\end{array}$ & $\begin{array}{l}\text { Oldukça iyi } \\
\text { Puan=1 }\end{array}$ & $\begin{array}{l}\text { Oldukça kötü } \\
\text { Puan=2 }\end{array}$ & $\begin{array}{l}\text { Çok kötü } \\
\text { Puan } 3\end{array}$ \\
\hline Uykuya dalma süresi & $\begin{array}{l}15 \mathrm{dk} \\
\text { altında } \\
\text { Puan=0 }\end{array}$ & $\begin{array}{l}16-30 \mathrm{dk} \\
\text { arasinda } \\
\text { Puan=1 }\end{array}$ & $\begin{array}{l}31-60 \mathrm{dk} \\
\text { arasında } \\
\text { Puan=2 }\end{array}$ & $\begin{array}{l}60 \mathrm{dk} \\
\text { üzeri } \\
\text { Puan =3 }\end{array}$ \\
\hline Uyku süresi & $\begin{array}{l}7 \text { saat ve } \\
\text { üzeri } \\
\text { Puan }=0\end{array}$ & $\begin{array}{l}6-6,9 \text { saat } \\
\text { Puan }=1\end{array}$ & $\begin{array}{l}5-5,9 \text { saat } \\
\text { Puan }=2\end{array}$ & $\begin{array}{l}5 \text { saat alt1 } \\
\text { Puan=3 }\end{array}$ \\
\hline $\begin{array}{l}\text { Alışılmış uyku etkinliği(uyku } \\
\text { süresi/yatakta kalma süresi x } \\
100\end{array}$ & $\begin{array}{l}\% 85 \text { üzeri } \\
\text { Puan }=0\end{array}$ & $\begin{array}{l}\% 75-84 \\
\text { Puan=1 }\end{array}$ & $\begin{array}{l}\% 65-74 \\
\text { Puan=2 }\end{array}$ & $\begin{array}{l}<\% 65 \\
\text { Puan=3 }\end{array}$ \\
\hline $\begin{array}{l}\text { Geçen ayda yaşanan uyku } \\
\text { bozukluğu sıllığ } 1\end{array}$ & $\begin{array}{l}\text { Hiç } \\
\text { yaşanmadi } \\
\text { Puan=0 }\end{array}$ & $\begin{array}{l}\text { Haftada } \\
1 \text { 'den az } \\
\text { Puan=1 }\end{array}$ & $\begin{array}{l}\text { Haftada 1-2 } \\
\text { defa } \\
\text { Puan=2 }\end{array}$ & $\begin{array}{l}\text { Haftada } 3 \\
\text { ve üzeri } \\
\text { Puan=3 }\end{array}$ \\
\hline $\begin{array}{l}\text { Geçen ayda yaşanan gündüz } \\
\text { işlev bozukluğunun sıklığ1 }\end{array}$ & $\begin{array}{l}\text { Hiç } \\
\text { yaşanmadi } \\
\text { Puan=0 }\end{array}$ & $\begin{array}{l}\text { Haftada } \\
1 \text { 'den az } \\
\text { Puan=1 }\end{array}$ & $\begin{array}{l}\text { Haftada } 1-2 \\
\text { defa } \\
\text { Puan=2 }\end{array}$ & $\begin{array}{l}\text { Haftada } 3 \\
\text { ve üzeri } \\
\text { Puan=3 }\end{array}$ \\
\hline Uyku ilacı kullanma & $\begin{array}{l}\text { Hiç } \\
\text { kullanmiyor } \\
\text { Puan=0 }\end{array}$ & $\begin{array}{l}\text { Haftadal'den } \\
\text { az } \\
\text { Puan=1 }\end{array}$ & $\begin{array}{l}\text { Haftada 1-2 } \\
\text { defa } \\
\text { Puan=2 }\end{array}$ & $\begin{array}{l}\text { Haftada } 3 \\
\text { ve üzeri } \\
\text { Puan=3 }\end{array}$ \\
\hline
\end{tabular}

HBS tanısı uluslar arası HBS çalışma grubunun belirlediği Tablo 2'de gösterilen tanı kriterleri kullanıldı. HBS tanısı için bu tanı kriterlerinin hepsinin pozitif olması gereklidir.

HBS derecelendirme skalası, 10 sorudan oluşmaktadır. Her bir sorudaki HBS şiddet değerleri, HBS'nin etkisinin olmaması (0 puan) ya da çok şiddetli HBS olması (4 puan) şeklinde 0 ile 4 puan arasında derecelendirildi. Böylece toplamda 0 ve 40 arasında değişen bir skor elde edilir. Skalaya göre 1-10 puan arası hafif, 11-20 puan arası orta derecede, 21-30 puan arası şiddetli, 31-40 puan arası çok şiddetli derecede HBS olduğunu göstermektedir (Tablo 3).

\section{Tablo 2. Uluslararsı HBS çalışma grubu tanı kriterleri.}

Parestezi ve/veya diestezi sebebiyle kol ve bacakların hareket ettirilmek istenmesi
Rahatsızlık veren duyumları yatıştırmak için devam eden motor huzursuzluk
İstirahatta (yatınca oturunca) şikayetlerinin ortaya çıkması veya artması, hareketle kısmi
rahatlama, geçici kaybolma
Akşam ve gece şikayetlerinin artması


Tablo 3. RLS şiddeti.

\begin{tabular}{|c|c|}
\hline $\begin{array}{l}\text { 1-RLS’nin bacak ve kollarınızda yarattığı rahatsızlığı genel } \\
\text { olarak nasıl derecelendirirsiniz? }\end{array}$ & $\begin{array}{l}\text { Çok şiddetli (4) } \\
\text { Şiddetli (3) } \\
\text { Orta (2) } \\
\text { Hafif (1) } \\
\text { Hiçbiri (0) }\end{array}$ \\
\hline $\begin{array}{l}\text { 2-RLS semptomlarınız sebebiyle oluşan gezinme ihtiyacınızı } \\
\text { genel olarak nasıl derecelendirirsiniz? }\end{array}$ & $\begin{array}{l}\text { Çok şiddetli (4) } \\
\text { Şiddetli (3) } \\
\text { Orta (2) } \\
\text { Hafif (1) } \\
\text { Hiçbiri (0) }\end{array}$ \\
\hline $\begin{array}{l}\text { 3-Gezinmek. RLS'nin kol ve bacaklarınızda yarattığı rahatsızlığı } \\
\text { ne oranda geçiriyor? }\end{array}$ & $\begin{array}{l}\text { Geçirmiyor (4) } \\
\text { Az geçiriyor (3) } \\
\text { Orta derecede geçiriyor (2) } \\
\text { Tam veya tama yakõn geçiriyor (1) } \\
\text { Geçirilecek HBS semptomu yok (0) }\end{array}$ \\
\hline $\begin{array}{l}\text { 4-RLS semptomları sebebi ile uyku bozukluğunuz ne kadar } \\
\text { şiddetli idi? }\end{array}$ & $\begin{array}{l}\text { Çok şiddetli (4) } \\
\text { Şiddetli (3) } \\
\text { Orta (2) } \\
\text { Hafif (1) } \\
\text { Hiçbiri (0) }\end{array}$ \\
\hline $\begin{array}{l}\text { 5-RLS semptomları sebebi ile gün içinde oluşan yorgunluk ve } \\
\text { uykusuzluğunuz ne kadar şiddetli idi? }\end{array}$ & $\begin{array}{l}\text { Çok şiddetli (4) } \\
\text { Şiddetli (3) } \\
\text { Orta (2) } \\
\text { Hafif (1) } \\
\text { Hiçbiri (0) }\end{array}$ \\
\hline 6-Genel anlamda RLS'niz ne kadar şiddetli idi? & $\begin{array}{l}\text { Çok şiddetli (4) } \\
\text { Şiddetli (3) } \\
\text { Orta (2) } \\
\text { Hafif (1) } \\
\text { Hiçbiri (0) }\end{array}$ \\
\hline 7-RLS semptomlarınızın sıklığı nedir? & $\begin{array}{l}\text { Çok sık(haftada 6-7 gün) (4) } \\
\text { Sık(haftada 4-5 gün) (3) } \\
\text { Bazen(Haftada 2-3 gün) (2) } \\
\text { Arada sõrada (Haftada } 1 \text { gün) (1) } \\
\text { Hiçbir zaman (0) }\end{array}$ \\
\hline $\begin{array}{l}\text { 8-RLS semptomlarınız olduğunda süre olarak ortalama ne kadar } \\
\text { şiddetli idi? ( } 24 \text { saatte) }\end{array}$ & $\begin{array}{l}\text { Çok şiddetli( } 8 \text { saat veya daha fazla) (4) } \\
\text { Şiddetli ( } 3.8 \text { saat) (3) } \\
\text { Orta ( } 2.3 \text { saat) (2) } \\
\text { Hafif ( } 1 \text { saatten az) (1) } \\
\text { Hiçbiri (0) }\end{array}$ \\
\hline $\begin{array}{l}\text { 9-Genel olarak RLS semptomlarınızın memnuniyet verici bir } \\
\text { aile, ev, sosyal, okul veya iş yaşamı sürdürme gibi günlük } \\
\text { işlerinizi gerçekleştirme kabiliyetiniz üzerindeki etkisi ne kadar } \\
\text { şiddetli idi? }\end{array}$ & $\begin{array}{l}\text { Çok şiddetli (4) } \\
\text { Şiddetli (3) } \\
\text { Orta (2) } \\
\text { Hafif (1) } \\
\text { Hiçbiri (0) }\end{array}$ \\
\hline $\begin{array}{l}\text { 10-RLS semptomlarınızdan kaynaklanan öfke, can sıkıntısı } \\
\text { korku, üzüntü ve huzursuzluk gibi ruh hali değişimleriniz ne } \\
\text { kadar şiddetli idi? }\end{array}$ & $\begin{array}{l}\text { Çok şiddetli (4) } \\
\text { Şiddetli (3) } \\
\text { Orta (2) } \\
\text { Hafif (1) } \\
\text { Hiçbiri (0) }\end{array}$ \\
\hline
\end{tabular}

\section{Ístatistiksel analiz}

Çalışmamızın verileri SPSS (veri 14,0) programına yüklenerek verilerin değerlendirilmesinde Khi-kare testi, korelasyon analizi kullanılarak, yanılma düzeyi 0.05 olarak alındi.

\section{Bulgular}

Çalışmaya 112 hasta alındı. Hastaların \%44,6'sı (50) erkek, \%55,4'ü (62) kadın idi. Hastaların yaş ortalaması 56,8 $( \pm 16,2)$ olarak belirlendi. Hastaların 44'sinde DM tanıs1 mevcuttu. Hastaların demografik ve labaratuvar bulguları Tablo 4 'te gösterilmiştir.

Hastaların \%66,1'inde (74 hastada) HBS tespit edildi. Hastaların \%61,6'sinda (69 hastada) uyku kalitesinde bozukluk tespit edildi. HBS pozitif olan 74 hastanın 55'inde uyku kalitesinde bozukluk tespit edildi. HBS ile uyku kalitesi bozukluğu arasında anlamlı bir ilişki tespit edildi ( $\mathrm{p}$ değeri 0,001). HBS tanısı konulan hastalarda HBS şiddeti değerlendirildiğinde 17 hastada orta, 25 hastada şiddetli ve 32 hastada çok şiddetli olarak değerlendirildi. HBS şiddeti ortalama $27,4 \pm 7,8$ olarak belirlendi. HBS ile uyku kalitesinde bozukluk arasındaki ilişki tablo 5 'te verildi. 
HBS ile hemodiyaliz süresi, anemi ve parathormon düzeyi arasında anlamlı bir ilişki saptanmadı ( $>0,05)$. Uyku kalitesinde bozukluk ile hemodiyaliz süresi, anemi ve parathormon, kalsiyum ve fosfor düzeyleri ile arasında anlamlı bir ilişki saptanmadı ( $>0,05)$. Uyku kalitesinde bozukluk ile yaş arasında anlamlı bir ilişki tespit edilmedi $(\mathrm{p}>0,05)$.

Tablo 4. Demografik ve labaratuvar bulguları.

\begin{tabular}{ll}
\hline Parametre & Standart sapma ( \pm range) \\
\hline Yaş & $56,8 \pm 16,2(19-86)$ \\
Kreatinin & $5,6 \pm 2,5(1,4-13,9)$ \\
Kalsiyum & $8,6 \pm 0,78(6,3-10,4)$ \\
Fosfor & $4,7 \pm 1,2(1,8-7,9)$ \\
PTH & $365,4 \pm 494,9(5,7-1900)$ \\
Hb & $11,2 \pm 1,5(7,5-16)$ \\
Htc & $34,4 \pm 5,0(23,4-51,0)$ \\
RLS şiddeti & $27,4 \pm 7,8(11-40)$ \\
Hemodiyaliz süresi (ay) & $66,1 \pm 56,3(3-228)$ \\
Ferritin & $863,2 \pm 530(63-3351)$ \\
Demir & $76,8 \pm 33,5(22-188)$ \\
Serum demir bağlama kapasitesi & $233 \pm 8,5(133-368)$ \\
Transferrin saturasyonu & $331 \pm 16,6(8-89)$ \\
\hline
\end{tabular}

Tablo 5. HBS ile uyku kalitesinde bozukluk.

\begin{tabular}{|c|c|c|c|c|c|}
\hline & & \multicolumn{2}{|l|}{ HBS } & \multirow{2}{*}{ Toplam } \\
\hline & & & Var & Yok & \\
\hline \multirow{4}{*}{ Uyku } & Bozuk & $\mathrm{S}$ & 55 & 14 & 69 \\
\hline & & $\%$ & $79,7 \%$ & $20,3 \%$ & $100,0 \%$ \\
\hline & Normal & S & 19 & 24 & \\
\hline & & $\%$ & $44,2 \%$ & $55,8 \%$ & $100,0 \%$ \\
\hline \multirow{2}{*}{\multicolumn{2}{|c|}{ Toplam }} & & 74 & 38 & \\
\hline & & $\%$ & $66,1 \%$ & $33,9 \%$ & $100,0 \%$ \\
\hline
\end{tabular}

\section{Tartışma}

Son dönem böbrek yetmezliği ile hemodiyalize tedavisinde olan hastalarda uyku problemleri sağlıklı bireylere göre daha fazladır. Son dönem böbrek yetmezliği hastaları çoğunlukla yatağa yattıktan sonra uyuyamama, uyuduktan sonra sık uyanma ve bacaklarında huzursuzluktan yakınmaktadır. Ankete dayalı çalışmalarda bu hastaların dörtte üçünden fazlasında uyku kalitesinde bozukluk saptanmaktadır. Kusleikaite ve arkadaşlarının, PUKİ kullanarak 81 hemodiyaliz hastasında yaptıkları çalışmada, uyku kalitesi kötü olanların sıklığ $\% 67,7$ bulunurken, Iliescu ve arkadaşlarının 63 hemodiyaliz hastasında yaptıkları çalışmada ise bu sıklık \%71 olarak bulunmuştur [11, 15]. Bizim çalışmamızda uyku kalitesinde bozukluk \%61,6 olarak diğer çalışmalarla benzer oranda tespit ettik.

Yaşla birlikte uyku kalitesinde bozukluk sıklığının arttığını gösteren çalışmalar vardır. Yaşlı popülasyonda, yaşla birlikte sıklığı artan fiziksel hastalıklara, ilaç kullanımına, primer uyku bozukluklarına ve yaşam tarzı değişikliğine bağlı olarak uyku kalitesinde bozukluk artmaktadır [16]. Ancak Iliescu ve arkadaşları kronik böbrek yetmezliği olan hastalarda uyku kalitesi ile yaş arasında bir ilişki bulamamışlardır [11]. Bizim çalışmamızda aynı şekilde yaş ile uyku kaliteside bozukluk arasında bir ilişki saptanmadı.

Düşük hemoglobin düzeyi ile bozulmuş uyku kalitesi arasında negatif ilişki SLEEPO çalışmasında bildirilmiştir. $\mathrm{Bu}$ çalışmada polisomnografi ile değerlendirilen 10 hemodiyaliz hastasında aneminin düzeltilmesinin uyku kalitesi ve uyku bozukluğu parametreleri üzerine etkisi araştırılmış ve aneminin düzeltilmesi ile uyku kalitesinin 
arttığı, gece uyanmalarında azalma olduğu, uykunun daha az parçalandığı böylece daha dinlendirici bir uyku sağlandığı ve gün içi uyuklamaların azaldığ1 gösterilmiştir [17]. Bizim çalışmamızda anemi sıklığı yüksekti fakat uyku kalitesinde bozukluk ve anemi arasında anlamlı ilişki saptanmadı (her iki grupta anemi fazlaydı).

Iliescu ve arkadaşları gerek kronik böbrek yetmezliği gerekse hemodiyaliz hastalarında yaptıkları çalışmalarda, cinsiyet farkı ile uyku kalitesi arasında ilişki saptamamışlardır [11]. Ancak epidemiyolojik çalışmalarda kadınlarda özellikle premenapozal ve postmenapozal dönemde, uyku kalitesinde bozuklukların erkeklerden daha sık olduğunu göstermişlerdir [17]. Bizim çalışmamızda cinsiyet faklılığı ile uyku kalitesinde bozukluk arasında anlamlı ilişki saptanmadı.

Huzursuz bacak sendromu, sağlıklı bireylerde \%5-10 sıklıkta görülürken, demir eksikliği veya böbrek yetmezliği olanlarda sıklığı \%80'e ulaşabilmektedir $[18,19]$. Ayrıca yaşla birlikte sıklı̆̆ artmaktadır. Yapılan çalışmalarda HD hastalarında HBS sıklığı, Amerika'da (\%20,8), Hırvatistan'da (\%60) olarak saptanmıştır [20, 21]. Türkiye'de Çölbay ve arkadaşlarının yaptığı 95 hemodiyaliz hastasının alındığı çalışmada HBS sıklığ1 \% 45,3 oranda (43 hastada) tespit edilmiştir. HBS ile uyku kalitesinin bozuklukları arasında anlamlı bir ilişki tespit edilmemiş fakat HBS'li hastalarda uyku kalitesinin, HBS olmayanlara göre anlamlı düzeyde kötü olduğu saptanmıştır [22]. Biz çalışmamızda HBS sıklığın $\% 66,1$ olarak tespit ettik.

HD hastalarında ise yaşın HBS gelişimi açısından bir risk faktörü olmadığına dair yayınlar bulunmaktadır [21]. Dikkat edilmesi gereken konulardan biri de diyaliz hastalarında başta üremik nöropati, periferik vasküler hastalıklar ve diabetik nöropati olmak üzere HBS ile karışabilecek pek çok sorunun beraber bulunmasıdır. Diyaliz başlangıç süresinin artması ile HBS'nin bağlantılı olduğuna dair bir yayın dışında HBS ile diyalize başlangıç süresinin bağlantı olmadığı yönünde yayınlar çoğunluktadır [23, 24]. Kore'de HD hastalarında yapılan araştırmada HBS'li hastaların şiddet skalasına göre hastaların \%84,8'i hafif ve orta derecede HBS'li grupta saptanmıştır [24]. Aynı çalışmada prediyaliz BUN seviyesi ile HBS şiddeti arasında pozitif korelasyon saptanmıştır. Hindistan'da yapılan başka bir çalışmada ise John Hopkins şiddet skalasına göre hastaların yarısında şiddetli HBS saptanmıştır [25]. Avrupa'da HBS'lu hastalarda yapılan çok merkezli başka bir çalışmada da Uluslararası HBS çalışma grubu şiddet skalasına göre ortalama HBS şiddeti 24,6 bulunmuştur [26]. Aksu tarafından Kayseri'de HBS'lu hastalarda yapılan çalışmada ise ortalama HBS şiddeti 21,7 bulunmuştur [27]. Bizim yaptığımız çalışmada HBS şiddet ortalaması 27,4 olarak tespit edildi. Bunların \%43,2'si çok şiddetli, \%33,7'si şiddetli ve \%23,1'i orta şiddetliydi.

Anemi ile HBS arasındaki ilişki Takaki'nin çalışmasında da gösterilmiş olup hemoglobin ile HBS sıklığının negatif korelasyon göstermekte olduğu saptanmıştır [28]. Colled-Sidel ve arkadaşları başta serum demiri olmak üzere fosfor, ferritin ve transferin ile HBS arasında bir ilişki olup olmadığını araştırmışlar sadece serum fosfor düzeyinin HBS'lu olgularda daha yüksek olduğunu ancak istatistiksel olarak anlamlı bir fark olmadığını bildirmişlerdir. Anemi de HBS semptomlarını arttırmaktadır [29]. Bizim hastalarda anemi ile HBS arasında anlamlı ilişki yoktu.

Sonuç olarak; uyku kalitesi hemodiyaliz hastalarında sıklıkla bozulmaktadır ve ayrıca HBS sıklığ 1 da hemodiyaliz hastalarında artmıştır. Bunların ikisi birden hastanın yaşam kalitesini olumsuz yönde etkilemektedir. Hemodiyaliz hastalarında sıklıkla takip edilmesi gereken bozukluklar olup uyku kalitesinde bozukluk ile HBS arasında anlamlı ilişki tespit edilmiştir. 


\section{Kaynaklar}

1. Bassetti CL, Mauerhofer D, Gugger M, Mathiss J, Hess CW. Restless legs syndrome: a clinical study of 55 patients. Eur Neurol 2001; 45: 67-74.

2. Krishnan PR, Bhatia M, Behari M. Restless legs syndrome in Parkinson's disdease: a case controlled study. Mov disord 2003; 18: 181-5.

3. O'Keeffe ST. Restless legs syndrome. Arch Intern Med 1996; 156: 243-8.

4. Tan EK, Ondo W. Restless legs syndrome: Clinical features and treatment. Am Med Sci 2000; 319: 397-403.

5. Walters AS, LeBrocq C, Dhar A, Hening W, Rosen R, Allen RP, Trenkwalder C. International Restless Legs Syndrome Study Group. Validation of international restless legs syndrome study group rating scale for restless legs syndrome. Sleep med 2003; 4: 121-32.

6. Desautels A, Turecki G, MontplaisirJ, Xiong L, Walters AS, Ehrenberg BL, Brisebois K, Desautels AK, Gingras Y, Johnson WG, Lugaresi E, Coccagna G, PicchiettiDL, Lazzarini A, Rouleau GA. Restless legs syndrome. Confirmation of linkage to chromosome 12q, genetic heterogeneity and evidence of complexity. Arch Neurol 2005; 62: 591-6.

7. Hui DS, Wong TY, Li TS, Ko FW, Choy DK, Szeto CC, Lui SF, Li PK. Prevalence of sleep disturbances in Chinese patient with end stage renal failure on maintenance hemodialysis. Med Sci Monit 2002; 8: 331-6.

8. Cirignotta F Mondini S, Santoro A, Ferrari G, Gerardi R, Buzzi G. Reliability of a questionnare screening restless legs syndrome in patients on chronic dialysis. Am. J. Kidney Dis 2002; 40: 302-6.

9. Cornella CL. Restless legs syndrome: Treatment with dopamiergic agents. Neurology 2002; 58: 87-92.

10. Germain A, Hall M, Krakow B, Katherine Shear M, Buysse DJ. A brief sleep scale for posttraumatic stress disorder: Pittsburgh sleep quality index addendum for PTSD. J Anxiety Disord 2005; 19: 233-44.

11. Iliescu EA, Coo H, McMurray MH, Meers CL, Quinn MM, Singer MA, Hopman WM. Quality of sleep and health-related quality of life in haemodialysis patients. Nephrol Dial Transplant 2003; 18: 126-32.

12. Beck SL, Schwartz AL, Towsley G, Dudley W, Barsevick A. Psychometric evaluation of the Pittsburg sleep quality index in cancer patients. J Pain Symptom Manage 2004; 27: 140-8.

13. Buysse DJ, Reynolds CF, Monk TH, Berman SR, Kupfer DJ. The Pittsburg sleep quality index: A new instrument for psychiatric practice and research. Psychiatry Res 1989; 28: 193-213.

14. Buysse DJ, Reynolds CF, Monk TH, Hoch CC, Yeager AL, Kupfer DJ. Quantification of subjective sleep quality in healthy elderly men and women using the Pittsburg Sleep Quality Index (PSQI) 1991; 14: 331-8.

15. Kusleikaite N, Bumblyte IA, Rezukeviciene L, Sedlickaite D, Rinkunas K. Sleep disorder and quality of life in patients on hemodialysis. Medicina (Kaunas) 2005; 41: 69-74.

16. Kamel NS, Gammack JK. Insomnia in the elderly: Cause, approach, and treatment. Am J Med 2006; 119: 463-9.

17. Ohayon M. Epidemiological study on insomnia in the general population Sleep 1996; 19: 7-15.

18. Walker S, Fine A, Kryger MH. Sleep complaints are common in a dialysis unit. Am J Kidney Dis 1995; 26: 751-6.

19. Hui DS, Wong TY, Li TS, Ko FW, Choy DK, Szeto CC, Lui SF, Li PK. Prevalence of sleep disturbances in Chinese patients with end-stage renal failure on continuous ambulatory peritoneal dialysis. Am J Kidney Dis 2000; 36: 783-8.

20. Unruh ML, Levey AS, D'Ambrosio C, Fink NE, Powe NR, Meyer KB. Restless legs symptoms among incident dialysis patients: association with lower quality of 
life and shorter survival. Am J Kidney Dis 2004; 43: 900-9.

21. Telarovic S, Relja M, Trkulja V. Restless legs syndrome in hemodialysis patients: Association with calcium antagonists. A preliminary report. Eur Neurol 2007; 58:166-9.

22. Çölbay M, Yüksel Ş, Acartürk G, Uslan I, Karaman O. Huzursuz bacak sendromlu hemodiyaliz hastalarında uyku kalitesi: Genel Tip Derg 2007; 17: 3541.

23. Gigli GL, Adorati M, Dolso P, Piani A, Valente M, Brotini S, Budai R. Restless legs syndrome in end-stage renal disease. Sleep Med 2004; 5: 309-15.

24. Kim JM, Kwon HM, Lim CS, Kim YS, Lee SJ, Nam H. Restless Legs Syndrome in Patients on Hemodialysis: Symptom Severity and Risk Factors. J Clin Neurol 2008; 4: 153-7.

25. Bhowmik D, Bhatia M, Gupta S, Agarwal SK, Tiwari SC, Dash SC. Restless legs syndrome in hemodialysis patients in India: a case controlled study. Sleep Med 2003; 4: 143-6.

26. Ferini-Strambi L, Aarskog D, Partinen M, Chaudhuri KR, Sohr M, Verri D, Albrecht S. Effect of pramipexole on RLS symptoms and sleep: A randomized, double-blind, placebo-controlled trial. Sleep Med 2008; 9: 874-1.

27. Aksu M, Demirci S and Bara-Jimenez W. Correlation between putative indicators of primary restless legs syndrome severity. Sleep Med, 2007; 8: 84-9.

28. Takaki J. Nishi T, Nangaku M, Shimoyama H, Inada T, Matsuyama N, Kumano $\mathrm{H}$, Kuboki T. Clinical and psychological aspects of restless legs syndrome in uremic patients on hemodialysis. Am J Kidney Dis 2003; 41: 833-9.

29. Collado-Seidel V, Kohnen R, Samtleben W, Hillebrand GF, Oertel WH, Trenkwalder C. Clinical and biochemical findings in uremic patients with and without restless legs syndrome. Am J Kidney Dis 1998; 31: 324-8. 